Tropical Journal of Pharmaceutical Research May 2020; 19 (5): 1099-1103

ISSN: $1596-5996$ (print); 1596-9827 (electronic)

(C) Pharmacotherapy Group, Faculty of Pharmacy, University of Benin, Benin City, 300001 Nigeria.

\title{
Effect of mesenchymal stem cell-incorporated hydroxyapatite-collagen scaffold on tissue repair in acute spinal cord injury, and the mechanism involved
}

\author{
Zhipeng Yao, Wenge Liu*, Chenyang Song \\ Department of Orthopedic, Fujian Medical University Union Hospital, Fuzhou, Fujian 350001, China
}

*For correspondence: Email: 609582848@qq.com; Tel: 0086-0591-83357896

Sent for review: 31 May 2019

Revised accepted: 20 April 2020

\begin{abstract}
Purpose: To study the effect of hydroxyapatite-collagen $(H C)$ scaffold with mesenchymal stem cells (MSCs) on tissue repair in acute spinal cord injury (SCI).

Method: Adult female Sprague-Dawley rats weighing 200 - $230 \mathrm{~g}$ were randomly divided into two groups implanted either with bone marrow-MSCs (experimental group) or HC scaffold alone (control group). Spinal cord injury was induced using laminectomy, resulting in a 2.0-mm gap at T10 of the spinal cord. The gap was filled in both groups with 2-mm HC scaffold at day 10 of culture. Cellular development, viability, and proliferation inside the scaffold were determined. Angiogenesis was determined by measuring fibronectin (FN) immunofluorescence, von Willebrand factor (vWF), hypoxiainducible factor 1-alpha (HIF-1 $\alpha$ ) and vascular endothelial growth factor (VEGF).

Results: HC scaffold strengthened MSCs. Bone marrow MSCs exhibited no statistically significant difference when compared with cells in culture at day $10(47.03 \pm 3.135 \%, p>0.05)$. Moreover, on days 5 and 10, FN deposition was higher in MSCs with scaffold than in scaffold-free MSCs. The expressions of FN, VWF, HIF-1a and VEGF were positively correlated, indicating that incorporation of HC scaffold into MSCs significantly improved tissue repair by improving angiogenesis via a differentiation process $(p<0.001)$.

Conclusion: These findings suggest that HC scaffold with MSCs is a potential therapeutic procedure for spinal cord injury.
\end{abstract}

Keywords: Mesenchymal stem cells, Hydroxyapatite-collagen, Spinal cord injury, HC scaffold

\begin{abstract}
This is an Open Access article that uses a fund-ing model which does not charge readers or their institutions for access and distributed under the terms of the Creative Commons Attribution License (http://creativecommons.org/licenses/by/4.0) and the Budapest Open Access Initiative (http://www.budapestopenaccessinitiative.org/read), which permit unrestricted use, distribution, and reproduction in any medium, provided the original work is properly credited.
\end{abstract}

Tropical Journal of Pharmaceutical Research is indexed by Science Citation Index (SciSearch), Scopus, International Pharmaceutical Abstract, Chemical Abstracts, Embase, Index Copernicus, EBSCO, African Index Medicus, JournalSeek, Journal Citation Reports/Science Edition, Directory of Open Access Journals (DOAJ), African Journal Online, Bioline International, Open-J-Gate and Pharmacy Abstracts

\section{INTRODUCTION}

Spinal cord injury $(\mathrm{SCl})$ is one of the most common causes of disability worldwide. Therefore, understanding CNS pathology after $\mathrm{SCl}$ is key to establishing an effective treatment [1]. Currently, several lines of clinical evidence show the clinical benefits of steroids in $\mathrm{SCl}$ treatment. However, stem cell-based therapy has produced some exciting and beneficial effects in the management of SCl. An array of MSCs with novel and promising strategies has been established from various sources for improvement of functional recovery after $\mathrm{SCl}$ [27]. Mesenchymal stem cells (MSCs) have been shown to promote the repair of injured spinal 
cord tissues in animal models. This has generated a lot of scientific interest in the clinical use of MSCs. It is well established that MSCs have ability to secrete several types of growth factors such as cytokines, NGF, chemokines, FGF, and BDNF which improve motor functions. Preclinical studies in animal models of SCI have demonstrated that MSC transplantation improves functional recovery after SCI [4-9]. These studies also showed that MSC transplantation is safe and is beneficial to $\mathrm{SCl}$ patients. The MSCs are not so difficult to obtain. The major problems faced by researchers are ethical concerns with respect to the use of MSCs. Studies have demonstrated that other than replacing harmed cells, MSCs have been used in several processes such as angiogenesis, immunosuppression, neuroprotection, and foundation of a profitable microenvironment for axonal recovery [2].

Fibronectin (FN), a glycoprotein, is present in blood plasma and extracellular matrices (ECMs). The major role of $\mathrm{FN}$ is in cell migration and attachment via cell surface receptors [3], due to its high affinity for collagen [4]. Therefore, MSC transplantation is one of the promising methodologies for recovery of disability after spinal line damage, through promoting angiogenesis. It is not known whether the use of HC scaffold with MSCs improves tissue repair process through differentiation and angiogenesis in rats with acute $\mathrm{SCI}$. Thus, the present study was designed to investigate whether the use of $\mathrm{HC}$ scaffold with mesenchymal stem cells would result in improved tissue repair process through differentiation and angiogenesis.

\section{EXPERIMENTAL}

\section{Animals and human tissue}

Adult female Sprague-Dawley rats weighing 200$230 \mathrm{~g}$ were obtained from the Laboratory Animal Center of Fujian Medical University. All experiments were performed after prior ethical approvals from the Animal Care Committee of Fujian Medical University (approval no. ACCEC/FMU/172/12D-2018). The CPCSEA guidelines were followed for animal care in all the study-related procedures [10]. Human bone marrow MSCs (hBM-MSCs were purchased from the Department of Orthopedics, Fujian Medical University Union Hospital, Fujian, China.

\section{Preparation of 3D hydroxyapatite-collagen scaffold for cell cultures}

Commercially available hydroxyapatite-collagen graft was used as scaffold. The material is clinically accepted as a bone graft substitute. The scaffold was sectioned into strips of 2-mm thick, round discs to facilitate nutrient delivery to the cells. The scaffold strips were decontaminated by washing with $75 \%$ ethanol, followed by washing thrice in PBS, and soaking in culture medium for $15 \mathrm{~min}$. A total of $1 \times 10^{6}$ cells was seeded into each $\mathrm{HC}$ scaffold strip and incubated at $37{ }^{\circ} \mathrm{C}$ in culture medium in a humidified atmosphere. The culture medium was replaced with fresh medium every $48 \mathrm{~h}$.

\section{Proliferation and viability of MSCs}

Cellular proliferation of MSCs in scaffolds was determined using MTT assay. Scaffolds with implanted MSCs were gently taken out at each time point (days 1-10) and rinsed twice in prewarmed $\left(37^{\circ} \mathrm{C}\right)$ PBS solution, followed by addition of MTT solution $(0.5 \mathrm{mg} / \mathrm{mL})$. The mixture was then incubated at $37^{\circ} \mathrm{C}$ for $4 \mathrm{~h}$ and the medium was discarded. Then, $300 \mu \mathrm{L}$ of DMSO was added to each well to solubilize the formazan crystals from the scaffolds. Absorbance of the solution was measured at 595 $\mathrm{nm}$. A growth curve was drawn by plotting absorbance values against number of days.

\section{Scanning electron microscopy (SEM) of scaffolds}

After 10 days, cultured MSCs on HC scaffolds were washed thrice with PBS buffer solution, and then fixed in $3 \%$ glutaraldehyde for $12 \mathrm{~h}$ at room temperature. The scaffolds were dehydrated in ethanol, air-dried, and sputter-covered with a 60$\mathrm{nm}$ layer of gold. They were then subjected to SEM (S-4700, Hitachi Ltd, Tokyo, Japan).

\section{Deposition of FN on scaffolds}

Western blot assay was used to determine the protein expression of FN. Onthe10th day in culture; scaffolds were rinsed severally with PBS buffer solution (PBS) and then cut into pieces using iris scissors. The pieces were further rinsed in lysis buffer containing protease and phosphatase inhibitor mixture using ultrasonic homogenizer. Polyacrylamide gel $(12.5 \%)$ was used for electrophoresis of $40 \mu \mathrm{g}$ of protein. The protein bands were transferred to a nitrocellulose membrane. The membrane was incubated $5 \%$ BSA in a mixture of tris-buffered saline (TBS) and Polysorbate 20 (TBST) to block non-specific binding of the blot. Thereafter, the membrane was incubated with anti-FN primary antibody for $2 \mathrm{~h}$. After washing with PBS, the membrane was incubated with HRP-conjugated secondary antibody for $2 \mathrm{~h}$. Finally, the membrane was washed once again, and the blots were identified 
with enhanced chemiluminescence (ECL). The expression of FN was normalized to that of betaactin gene which served as internal control.

\section{Spinal cord injury model and transplantation of MSCs-scaffold}

For the preparation of the SCl model, a total of 20 adult female Sprague-Dawley rats weighing 200 - $230 \mathrm{~g}$ were used. The rats were provided by the animal facility of Fujian Medical University, China. The animals were randomly divided into two groups, and implanted either with bone marrow MSCs (experimental groups) or HC scaffold alone (control group). Pentobarbitone anesthesia was used at a dose of $40 \mathrm{mg} / \mathrm{kg}$, ip. Laminectomy was performed, resulting in a 2$\mathrm{mm}$ gap at the level of T10of the spinal cord. The gap was filled with 2-mm HC scaffolds at day 10 of culture. The gap filling was done in both the experimental and control groups. The rats received post-operation care. Once they recovered after surgery, the rats were allowed to move freely in their cages.

\section{Immunohistochemistry}

The rats were sacrificed using decapitation after the first and second months of MSCs-scaffold transplantation. The spinal cord was perfused using a solution containing $0.002 \%$ heparin and $\mathrm{NaNO}_{2}$, and then fixed using $4 \%$ paraformaldehyde in phosphate buffered saline. Segments of pre-fixed spinal cord (T8-T12, 30 $\mathrm{mm}$ each) were incubated with the following primary antibodies: anti-HIF-1 $\alpha$, anti-FN, antivWF, and or anti-VEGF at $4{ }^{\circ} \mathrm{C}$ for $2 \mathrm{~h}$. This was followed by incubation with secondary antibody at $37^{\circ} \mathrm{C}$ for $1 \mathrm{~h}$. The slides were observed under fluorescence microscope (Nikon, Japan). The nuclei were counterstained with Hoechst 33342 dye.

\section{Statistical analysis}

Data are presented as mean \pm SD. Statistical analysis was done using one-way ANOVA. All statistical analyses were carried out using statistical software (GraphPad Prism, version 6.0 , USA). Statistical significance was assumed at $p<0.05$.

\section{RESULTS}

\section{Distribution of MSCs within HC scaffolds}

After progressive passages, cultured MSCs turned out to be generally homogeneous. At fourth passage, the cells showed fibroblast-like structures (after achieving $80 \%$ of target. Results from viability and proliferation using MTT assay revealed that cell population within the scaffold increased time-dependently up to 10 days (Figure $1 \mathrm{~A}$ ). At day 10, there was no statistically significant difference in proliferation between bone marrow MSCs and cells in culture (47.03 \pm $3.135 \%, p>0.05$ ) (Figure $1 \mathrm{~B}$ ).

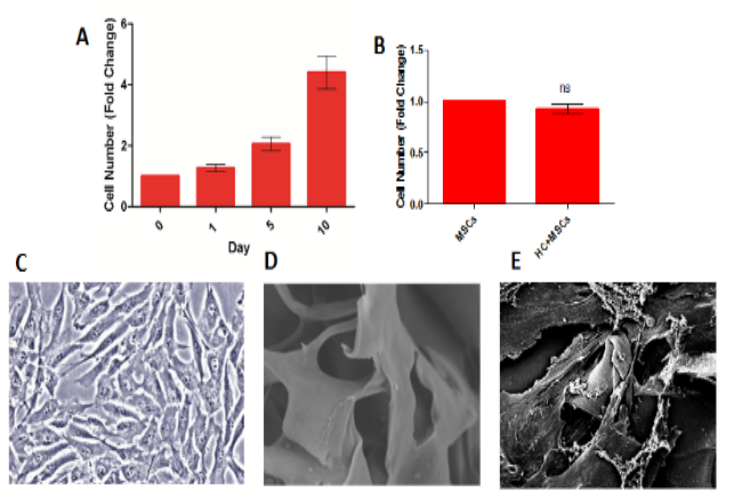

Figure 1: Structural features of $\mathrm{HC}$ scaffolds and MSCs. Figure $1 \mathrm{~A}$ shows cell viability of MSCs within the scaffold, as determined using MTT assay. Figure 1Bshowscomparative growth and viability of MSCs in culture disc and within the $\mathrm{HC}$ scaffold. Figure $1 \mathrm{C}-1 \mathrm{E}$ shows SEM showing multiparous structure of the HC scaffold. Figure 1E shows SEM showing adherence of MSCs to the scaffold. Scale bar (A): $40 \mu \mathrm{m}$. Scanning Electron Microscopy found that the cells developed into monolayers and released extracellular matrix proteins (Figure 1C-1E). On day 5 and day10, FN deposition was higher in MSCs-scaffold than in MScs without the scaffold

\section{Western blot results}

Figure 2 shows that FN deposition within the scaffold was higher on day 10 than on day 5 , and FN depositions within the scaffold on day 5 and day 10 were higher than that in MSc culture flasks without scaffolds.

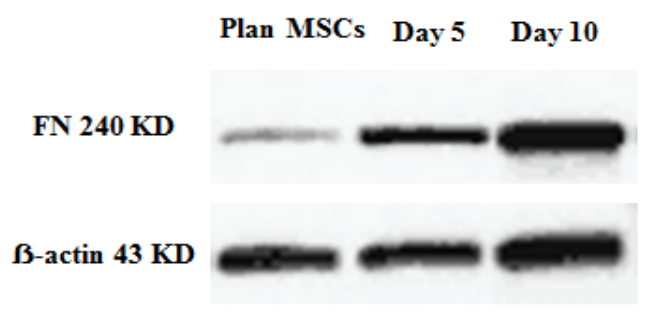

Figure 2: Level of $\mathrm{FN}$ expression, as determined using Western blot

\section{Neovascularization}

Neovascularization (angiogenesis) through expressions ofHIF-1a, vWF and VEGF was also observed. In Figure $3 \mathrm{~A}$, the red fluorescence indicates the expression of VWF. The MSCs 
surrounding blood vessels expressed VEGF (green fluorescence) (Figure $3 \mathrm{~B}$ ). Figure $3 \mathrm{C}$ shows the expression of HIF-1 $1 \alpha$.
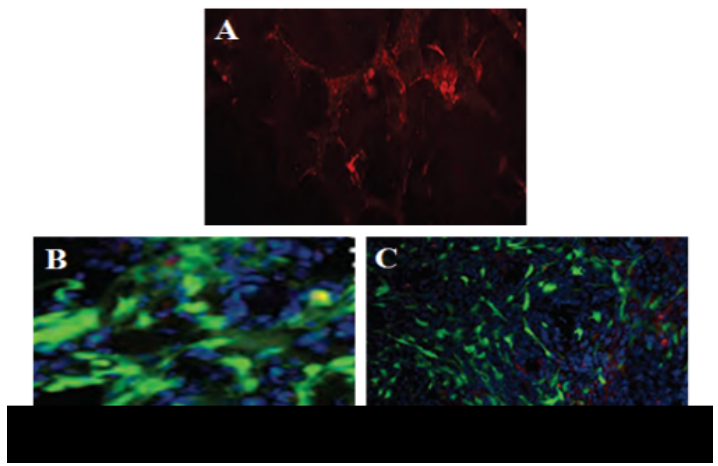

Figure 3: Immunofluorescence showing expressions of FN, vWF, HIF-1 $\alpha$ and VEGF). (A) On day 10, FN was deposited within the GS scaffold, as revealed by red fluorescence. Red fluorescence indicates the expression of VWF; (B) immunostaining showing neovascularization of the graft of $\mathrm{SCl}$ injury site in the $\mathrm{SCl}$ group (green fluorescence) green fluorescence which indicates the expression of VEGF; (C) Expression of HIF-1a. Scale bar: $40 \mu \mathrm{m}$

\section{DISCUSSION}

This is the first study designed to determine whether the use of HC scaffold with MSCs improves tissue repair process through differentiation and angiogenesis in a rat model of acute $\mathrm{SCl}$. Earlier pre-clinical reports showed that MSC transplantation improved functional recovery in animal model of $\mathrm{SCl}$. The present study was designed to investigate the synergistic effect of $\mathrm{HC}$ scaffold with MSCs in tissue repair for spinal cord injury. In this study, it was found that the use of HC scaffold was safe for patients. Indeed, this scaffold is already in use in medical practice. One more scientific advantage of HC scaffold is its affinity for cells, and its histocompatibility. Furthermore, MSCs can be sustained for 50 days in a 3D scaffold of collagen [5].

The results obtained in this study demonstrate that $\mathrm{HC}$ scaffold offers satisfactory availability of oxygen and nourishment in vitro and in vivo during vascularization. The possibility of developing a homogeneous situation for implantation is another basic idea for using this biomaterial. The expressions of FN, vWF, HIF-1a and VEGF were positively correlated, indicating that the addition of $\mathrm{HC}$ scaffold to MSCs significantly improved tissue repair by improving angiogenesis through differentiation process. These results are consistent with previous reports $[6,7]$.
Mesenchymal stem cells (MSCs are believed to revamp their substrate by releasing extended proportions of $\mathrm{FN}$ and collagen (type I) to the substrate [7]. Thus, it may be assumed that the MSC-bound scaffold released FN, which was deposited on scaffold, thereby initiating angiogenesis. This is consistent with previous reports $[8,9]$. Biomaterial vascularization is vital because adequate perfusion of blood permits cells situated at the focal point of the scaffold to obtain enough oxygen. Studies have revealed that the expression of HIF-1a by MSCs triggers angiogenesis [11,12]. Furthermore, it was hypothesized that decreased oxygen supply in the injured site causes lipid peroxidation and free radical generation [13].

Decreased levels of calcium, magnesium sodium and potassium enhance the expression ofHIF-1 $\alpha$, and hence angiogenesis [14-16]. In summary, a 3D HC scaffold was developed in this study, and it supported the viability and proliferation of MSCs.

Moreover, it was observed that $\mathrm{FN}$ was deposited on the scaffold. At the point when it was transplanted to transected site of the rodent spinal cord, the scaffold was observed to be biocompatible and ready to attach to the spinal cord. Transplantation of the scaffold with MSCs advanced angiogenesis by initiating blood vessel development and expressions of HIF-1 a, vWF and VEGF in the damaged zone of the spinal cord. The 3D HC scaffold may serve as a potential supporting biomaterial for recovering motor function after SCl.

\section{CONCLUSION}

The findings of this study demonstrate that $\mathrm{HC}$ scaffold strengthens MSCs. This indicates that in rats with acute $\mathrm{SCl}$, on addition of $\mathrm{HC}$ scaffold to MSCs significantly improves tissue repair process through differentiation and angiogenesis. Thus, MSC-incorporated HC scaffold is a potential remedial procedure for $\mathrm{SCl}$.

\section{DECLARATIONS}

\section{Conflict of interest}

No conflict of interest is associated with this work.

\section{Contribution of authors}

We declare that this work was done by the authors named in this article and all liabilities 
pertaining to claims relating to the content of this article will be borne by the authors. This paper was drafted by Zhipeng Yao. All the experiments are performed by Zhipeng Yao under supervision of Wenge Liu. Chenyang Song collected materials for this study.

\section{Open Access}

This is an Open Access article that uses a funding model which does not charge readers or their institutions for access and distributed under the terms of the Creative Commons Attribution License (http://creativecommons.org/licenses/by/ 4.0) and the Budapest Open Access Initiative (http://www.budapestopenaccessinitiative.org/rea d), which permit unrestricted use, distribution, and reproduction in any medium, provided the original work is properly credited.

\section{REFERENCES}

1. Wyndaele M, Wyndaele JJ. Incidence, prevalence and epidemiology of spinal cord injury: what learns a worldwide literature survey? Spinal cord 2006;44(9):523-529.

2. Parr AM, Tator $\mathrm{CH}$, Keating A. Bone marrow-derived mesenchymal stromal cells for the repair of central nervous system injury. Bone Marrow Transplant2007;40(7):609-619.

3. Ahmed Z, Underwood S, Brown RA. Nerve Guide Material Made from Fibronectin: Assessment of in Vitro Properties. Tissue Eng 2003; 9(2):219-231.

4. Balian G, Click EM, Bornstein P. Location of a collagenbinding domain in fibronectin. J Biol Chem 1980; 255(8):3234-3236.

5. Neuss S, Stainforth $R$, Salber J, Schenck $P$, Bovi M, Knüchel R. Long-Term Survival and Bipotent Terminal Differentiation of Human Mesenchymal Stem Cells (hMSC) in Combination with a Commercially Available Three-Dimensional Collagen Scaffold. Cell Transplant 2008; 17(8):977-986.

6. Moore KA. Stem Cells and Their Niches. Science2006; 311(5769):1880-1885.

7. Kundu AK, Khatiwala CB, Putnam AJ. Extracellular Matrix Remodeling, Integrin Expression, and Downstream Signaling Pathways Influence the Osteogenic Differentiation of Mesenchymal Stem Cells on Poly(Lactide-Co-Glycolide) Substrates. Tissue Eng Part A 2009; 15(2):273-283.

8. Winkler $T$, Sharma HS, Gordh $T$, Badgaiyan RD, Stålberg E, Westman J. Topical application of dynorphin A (1-17) antiserum attenuates trauma induced alterations in spinal cord evoked potentials, microvascular permeability disturbances, edema formation and cell injury. Amino Acids2002; 23(1-3):273-281.

9. Imperato-Kalmar EL, McKinney RA, Schnell L, Rubin BP, Schwab ME. Local Changes in Vascular Architecture Following Partial Spinal Cord Lesion in the Rat. Exp Neurol.1997; 145(2):322-328.

10. Committee for the Purpose of Control and Supervision on Experiments on Animals. CPCSEA guidelines for laboratory animal facility. Indian J Pharmacol 2003; 35: 257-274

11. Lord-Dufour S, Copland IB, Levros L-C, Post M, Das A, Khosla C. Evidence for Transcriptional Regulation of the Glucose-6-Phosphate Transporter by HIF-1a: Targeting G6PT with Mumbaistatin Analogs in Hypoxic Mesenchymal Stromal Cells. Stem cells2009; 27(3):489497.

12. Okuyama $H$, Krishnamachary B, Zhou YF, Nagasawa $H$, Bosch-Marce M, Semenza GL. Expression of Vascular Endothelial Growth Factor Receptor 1 in Bone Marrowderived Mesenchymal Cells Is Dependent on Hypoxiainducible Factor 1. J. Biol. Chem2006; 281(22):1555415563.

13. Bao F, John SM, Chen Y, Mathison RD, Weaver LC. The tripeptide phenylalanine-(d) glutamate-(d) glycine modulates leukocyte infiltration and oxidative damage in rat injured spinal cord. Neuroscience 2006; 140(3):10111022.

14. Schmedtje JJF, Liu WL, Ji Y, Thompson TM, Runge MS. Evidence of Hypoxia-Inducible Factor-1 in Vascular Endothelial and Smooth Muscle Cells. Biochem Biophys Res Commun 1996; 220(3):687-691.

15. Du R, Lu KV, Petritsch C, Liu P, Ganss R, Passegué E, et al. HIF1a Induces the Recruitment of Bone MarrowDerived Vascular Modulatory Cells to Regulate Tumor Angiogenesis and Invasion. Cancer cell 2008; 13(3):206-220.

16. Kido M, Du L, Sullivan CC, Li X, Deutsch R, Jamieson SW. Hypoxia-Inducible Factor 1-Alpha Reduces Infarction and Attenuates Progression of Cardiac Dysfunction After Myocardial Infarction in the Mouse. J Am Coll Cardiol2005; 46(11):2116-2124. 